\title{
Las migraciones en el norte de Veracruz, México. Redes, rutas y ruralidades*
}

\author{
Migration in the north of Veracruz, Mexico: networks, routes and rural \\ dimensions \\ Mario Pérez Monterosas** \\ Universidad Autónoma Metropolitana-Azcapotzalco \\ México
}

Recibido: 17 de mayo de 2017. Aprobado: 5 de junio de 2018

\begin{abstract}
Resumen
Este artículo aborda la dinámica de las redes sociales en el proceso de origen y reproducción de la migración internacional emergente, acelerada y heterogénea, que ha tenido lugar en el norte de Veracruz, México, en la última década del siglo XX y principios del XXI. El análisis se centra en las migraciones de los campesinos e indígenas totonacos, de la sierra papanteca. La discusión se apoya en los planteamientos teóricos de la migración como proceso social, en las redes sociales como marco para las interacciones de los actores rurales que han establecido espacios de trabajo y de vida entre los municipios de la sierra y la región, así como en las ciudades del centro del país, la frontera norte, Estados Unidos y Canadá. Esta investigación se sustenta en información bibliográfica y en la obtenida por medio de trabajo de campo en diversas comunidades rurales de la sierra de Papantla, en el norte-centro de Veracruz. Damos cuenta de los diversos tipos de movilidades de los actores rurales que en su ir y venir modifican las conductas y expectativas de sus contextos de origen.
\end{abstract}

Palabras clave: migración, sociedades rurales, México.

\begin{abstract}
This article addresses the dynamics of social networks in the process of origin and reproduction of the emerging, accelerated and heterogeneous international migration that has taken place in the north of Veracruz, Mexico, in the last decade of the 20th century and the beginning of the $21 \mathrm{st}$. The analysis focuses on the migrations of the Totonac peasants and

* $\quad$ Proyecto "Interacciones sociales y cambio sociocultural en los circuitos migratorios del centro y norte de Veracruz a los Estados Unidos a finales del siglo XX e inicios del XXI" (Folio: UAM-PTC-542). PROMEP-Secretaría de Educación Pública, noviembre de 2015-julio de 2017. Agradecemos la colaboración reflexiva de la socióloga Diana Berenice Esquivel Saldaña.

** Maestro en estudios rurales, El Colegio de Michoacán; sociólogo y doctor, Universidad Veracruzana. Profesor investigador, Universidad Autónoma Metropolitana-Azcapotzalco. Investigador Nacional Nivel 1. Correo electrónico: marpezrosa@gmail.com
\end{abstract}


indigenous people of the Sierra Papanteca. The discussion is based on the theoretical approaches to migration as a social process, in social networks as a framework for the interactions of rural stakeholders who have established working and living spaces between the municipalities of the sierra (highlands) and the region, as well as with the cities in the center of the country, the northern border, the United States and Canada. The investigation is based on bibliographic information and on that obtained through field work in various rural communities located in the Sierra Papantla in north-central Veracruz. The article illustrates the different types of mobility of rural actors who, in their comings and goings, modify the behaviors and expectations of their contexts of origin.

Keywords: migration, rural societies, Mexico.

\section{Introducción}

La vieja y permanente movilidad de hombres y mujeres indígenas de la sierra del Totonacapan veracruzano ha dejado su huella en las formas de trabajo, interacción social y construcción de expectativas de los jóvenes, quienes han recurrido a estrategias distintas a las agrícolas para participar más activamente en los mercados de trabajo urbano en ciudades lejanas y durante ausencias de larga duración o permanentes. Esto ha traído consigo la aceleración de procesos socioculturales y económicos debido a la incorporación de los indígenas y campesinos a las emergentes migraciones de finales de la década de 1980 y hasta el día de hoy, con destino a Estados Unidos, así como la movilidad laboral hacia Canadá, regulada por el Estado mexicano.

Durante la segunda mitad del siglo XX y los inicios del XXI, la movilidad geográfica de los indígenas totonacos ha venido redefiniéndose de manera importante respecto del perfil de los migrantes, causas, redes sociales, sus expectativas y proyectos.

Los movimientos migratorios de los indígenas son multicausales, pero las condiciones económicas y estructurales de las localidades de origen han jugado un factor determinante, debido a la existencia de un medio rural descapitalizado, nulas oportunidades laborales locales, falta de apoyos y de recursos gubernamentales (Griego, Muñoz, Pérez, y Salazar, 2003), y de las condiciones propicias para la producción agrícola y la comercialización (Moctezuma, 2008).

La circulación de personas, bienes, dinero, regalos, sueños y formas de apropiarse del cuerpo, entre los contextos rurales de origen y las áreas urbanas de destino, han modificado las formas sociales de relacionarse, de divertirse, de convivir y concebir el futuro. En ocasiones, todo lo anterior tiene efectos favorables o costosos, dependiendo de la propia perspectiva de sus protagonistas.

Este trabajo pretende contribuir al conocimiento sobre las motivaciones de las migraciones, sus dinámicas de movilidad geográfica, culturas del trabajo, y procesos de cambio y permanencia, que tienen lugar entre los indígenas totonacos de Veracruz, México. 
La presente investigación se apoya en los hallazgos del trabajo de campo realizado entre junio de 2011 y marzo de 2016, en diferentes recorridos a través de algunas localidades de los municipios de Coyutla, Mecatlán y Filomeno Mata, que, junto con Chumatlán, Coahuitlán, Coxquihui y Zozocolco, conforman la Sierra de Papantla. La información se ha obtenido a través de técnicas etnográficas, tales como entrevistas abiertas y dirigidas, observación participante, fotografía, cartografía y consulta bibliográfica. Se realizaron entrevistas a mujeres y hombres, a jóvenes indígenas, migrantes y no migrantes, sobre temas como el trabajo local y los procesos de movilidad y migración nacional e internacional, reglamentada e indocumentada.

Considerando que nos ubicábamos en una región "movediza", fue pertinente plantear interrogantes que nos brindaran información sobre las formas, tiempos y espacios en los que los totonacos se desplazaban en busca de trabajo, no solo en la región y a nivel nacional, sino también en Estados Unidos. Aquí nos hemos apoyado en los planteamientos que hicieron Gatti y Chenaut (1987) para analizar la región del totonacapan en la década de 1980.

\section{Las redes sociales en los procesos de migración internacional}

La migración había venido explicándose mediante teorías macro que consideraban que los factores que la generaban eran netamente económicos, excluyendo la posibilidad de que otras perspectivas o enfoques emitieran su propia explicación, lo cual era una gran limitante. Portes y Rumbaut (1995) analizaron la migración como un "problema social", y consideraron los procesos de asentamiento en los lugares de destino y la pertenencia étnica de los inmigrantes. Por su parte, Tilly (1990) dio cuenta de cómo las redes sociales transformaban las relaciones sociales y creaban nuevos grupos de identidad, solidaridad y desigualdad.

Las acciones económicas están orientadas socialmente por las expectativas de reciprocidad en las que las interacciones sociales cumplen una función de gran importancia, por ello consideramos que la migración, al tener un significado social, se intensifica en los tejidos y vínculos que se establecen entre los actores en función de los motivos y aspiraciones que se generan al estar en contacto con migrantes activos o de retorno, a través no solo de relaciones cara a cara, sino también virtuales, facilitadas por los medios de comunicación y por formas modernas de transmisión de imágenes y mensajes (Portes y Rumbaut, 1995) por parte de quienes se encuentran entre México y Estados Unidos.

Massey, Alarcón, Durand y González (1987) propusieron analizar la migración como un proceso social en el que juegan un papel importante las redes sociales y el capital social y humano, como elementos que la perpetúan y autosostienen a nivel internacional. La migración de mexicanos hacia Estados Unidos tiene ya una larga data: desde hace más de un siglo se han presentado flujos de carácter laboral en el occidente de México, como resultado de un proceso social, dinámico y complejo que ha introducido cambios en los ámbitos individual, familiar y comunitario (Durand, 1994; Massey et al., 1987; Wiest, 1977). Massey et al. (1987) consideran que la migración genera más migración a lo largo del tiempo 
mediante un poderoso impulso de auto mantenimiento, que culmina en una migración cada vez mayor.

La constante interacción inherente a la migración entre México y Estados Unidos da paso a la formación de un circuito migratorio por donde circulan personas, bienes, dinero, información e ideas, creándose vínculos entre las comunidades de origen, tránsito, estancia temporal, de destino y retorno, hasta formar un sistema de diversas redes que permiten disminuir los costos sociales y humanos, fomentando así más migración (Wiest, 1977). Esta, a su vez, transforma las motivaciones individuales, las estrategias familiares y las estructuras de la comunidad. La migración se organiza de manera social e informalmente con base en las interacciones de los actores, migrantes o no migrantes, y se extiende en el tiempo, convirtiéndose de fenómeno aislado en masivo, en el que se incluye o excluye la participación de unos y otros.

Las redes han permitido la estructuración de la experiencia colectiva de la migración, desarrollando y socializando un aprendizaje colectivo sobre rutas, tiempos, condiciones de empleo, peligros, riesgos, contactos, formas de comportamiento, y un conjunto de conocimientos (Velasco, 2002), lo que representa una fuente importante de poder e influencia entre los diferentes actores (Castilla, Hwang, Granovetter y Granovetter, 2000).

\section{La migración internacional en Veracruz: finales y principios de siglos}

La presencia acelerada de la migración internacional en la conformación de los flujos actuales en regiones emergentes, se hace evidente cuando se compara con los patrones tradicionales del occidente de México, que requirieron de una inversión mayor de años para su desarrollo. Podríamos citar el caso de los indígenas michoacanos; entre ellos, el "movimiento de masa" les llevó dos décadas (Kemper, 1987), mientras que en las nuevas migraciones emergentes de finales del siglo XX se han desarrollado en menos de una década, como es el caso de los veracruzanos que llegaron sin ayuda a Los Angeles, con un capital social muy pobre y con acceso a empleos mal remunerados (Ibarra, 2003). A lo largo del siglo XX, Veracruz ha ido perdiendo gradualmente su importancia como estado receptor de inmigrantes nacionales y extranjeros, para convertirse en un expulsor, primero por las migraciones intraestatales y nacionales de jornaleros agrícolas, y segundo como expulsor a la frontera norte, con destino a Estados Unidos y Canadá, de grupos de personas de origen tanto urbano como rural.

La década de 1990 destaca como la más importante en la expulsión de veracruzanos hacia Estados Unidos, debido a la aparición y al desarrollo de flujos densos, de composición heterogénea y de manera acelerada (Pérez, 2013). Lo mismo ha venido ocurriendo en otros estados del país como Hidalgo, Chiapas, Tabasco, Estado de México, Puebla, los que consideramos emergentes, entendiendo por estos a los que tienen una presencia importante y acelerada de conformación de sus flujos a partir de los años noventa. Estos se dirigían a diversos lugares de destino, tanto urbanos como rurales, y son de nueva participación en la migración de carácter internacional. 
Entre 1995 y 2000, el estado de Veracruz aportó a la migración hacia Estados Unidos el 4,8\% del total, ocupando el sexto lugar después de Jalisco, Michoacán, Guanajuato, México y el Distrito Federal. En 1996, la región sureste de México, conformada por los estados de Tabasco, Chiapas, Campeche, Veracruz, Yucatán y Quintana Roo, contribuyó con apenas el 2\% de la migración total hacia Estados Unidos (Secretaría de Relaciones Exteriores, 1997).

De los 210 municipios que conforman Veracruz, en el año 2000 se identificaron 121 con muy baja migración, 67 con baja, 17 con media, 3 de alta y 2 de muy alta (Conapo, 2002). Según datos de la muestra censal del año 2000, más de 80 mil veracruzanos salieron del estado entre 1995 y 2000, 75 mil de los cuales se dirigieron a Estados Unidos (INEGI, 1995, 2000). En el año 2000, aproximadamente un millón de veracruzanos se había ido a Estados Unidos, un $12,5 \%$ del total de la población del estado, ubicándose en el cuarto lugar después de Oaxaca, México y Puebla (COESPO, 2002; González, 2006). Es una posición importante si consideramos que en 1997 ocupaba el lugar número 30 dentro de la lista de estados expulsores de migrantes a Estados Unidos, lo que representaba el 1,9\% de la población total del estado.

Para el año 2010 se registraron dos municipios con índices de intensidad muy altos, 21 con alto, 40 con medio, 80 con bajo, 68 con muy bajo y uno con grado nulo. Las variaciones entre los años 2000 y 2010 no solo refieren al incremento de grados inferiores a superiores, sino al posicionamiento ascendente de unos municipios y a la pérdida de importancia de otros, a causa de la dinámica cambiante en el tiempo y la dimensión de sus flujos. Los casos que llaman la atención son los municipios de Tenampa y Texhuacan, los que en 2000 tenían grado migratorio muy bajo y una década después ocuparon uno muy alto (INEGI, 2010). Una muestra de la presencia acelerada y del desarrollo del proceso migratorio internacional en Veracruz se hace evidente en el posicionamiento que ha tenido en la lista de expulsión de población a Estados Unidos, pues en tan solo un quinquenio pasó de un lugar por debajo del número 15 a la cuarta posición.

En el año 2000, los municipios de la Sierra de Papantla se ubicaban en el índice de intensidad migratoria internacional de la siguiente manera: Coyutla, Espinal, Filomeno Mata y Mecatlán como muy bajo, y Coxquihui como nulo (INEGI, 2000). Para el 2010, Coxquihui ascendió a muy bajo, conservándolo Filomeno Mata y Mecatlán, mientras que Coyutla descendió a la categoría de bajo (INEGI, 2010).

Una variable importante en la migración internacional son las remesas. Tomaremos a estas como muestra para destacar la acelerada participación de Veracruz, que en 1995 captó 76 millones de dólares, lo cual la ubicó en el lugar 15. Para el año 2000, 45.319 hogares recibieron remesas procedentes de Estados Unidos; en el 2002, se captaron 200 millones de dólares; para el año 2005 hubo un incremento, al captar 1.154 millones de dólares; en 2007 alcanzó los 1.800 y 1.269 millones en 2011 (Pérez, 2013). En los últimos años, el estado de Veracruz se ha ubicado en los primeros siete lugares como receptor de remesas, al igual que como estado expulsor de migrantes. La reciente migración por motivos laborales tiene como destino la frontera norte del país, donde se emplean en las maquiladoras en los estados de 
Illinois, California, Texas, Carolina del Sur, Carolina del Norte, Nueva York y Georgia, en Estados Unidos (Pérez, 2013; Cruz, 2012).

Los municipios de origen de los inmigrantes que se dirigieron a la frontera norte hacia 20002001, y que se ubican circundantes a la región de la Sierra de Papantla, son las siguientes: con un porcentaje importante contribuían las ciudades de Poza Rica y Xalapa (10\%), Veracruz (7\%), Cerro Azul (6\%), Tuxpam (5\%); a estos seguían Papantla y Panuco (4\%), y otros municipios con un total de 49\%. Los diez concentran el 51\% del total (EMIF, 2004). Para 2005-2006, el aporte porcentual se modifica del siguiente modo: Poza Rica desciende al 9\%, Veracruz al 9\%, Xalapa al 5\%, Cerro Azul y Tuxpam al 5\%, Naranjos al 6\%, Panuco y Papantla al 4\%; el resto de los municipios aportan el 50\%, mientras que los diez municipios concentran el 50\% del total (EMIF, 2008). Para 2010-2011, Poza Rica asciende a 12\%, Cerro Azul crece hasta el 10\%, Veracruz al 5\%, Xalapa al $7 \%$, Naranjos al 5\%; Tuxpam, Panuco y Papantla al 4\%; Temapáche pasó del 2\% anterior al 3\%. El 45\% lo aporta el resto de los municipios, mientras que los diez municipios concentran el 55\% del total. Los porcentajes refieren a eventos migratorios y no a personas (EMIF, 2013).

Llaman la atención los municipios que envían migrantes a la frontera norte, pues estos se ubican en la parte norte del estado, en la región denominada totonacapan. Allí se encuentra la ciudad petrolera de Poza Rica, la cual, a raíz de la crisis en el sector, devino en un expulsor importante de mano de obra. La mayor parte de los migrantes veracruzanos que van al norte se dirigen a la frontera, y solo un tercio en promedio opta por Estados Unidos (Mestries y Pérez, 2014). Es notorio el hecho de que para los períodos analizados los municipios de origen se concentran en la región denominada como totonacapan, compuesta por población rural, indígena y obreros especializados relacionados con la industria petrolera. Sin embargo, los municipios que aportan porcentajes importantes de población a los flujos no son siempre los mismos: hay cambios constantes, lo que hace más complejo el análisis del fenómeno.

\section{Las redes migratorias en las ruralidades indígenas veracruzanas}

Los indígenas y habitantes del medio rural veracruzano estaban acostumbrados a su economía de autoconsumo, a la venta de sus artesanías y a salir en busca de trabajo en la ciudad y en áreas agrícolas del interior del estado o del país. Sin embargo, a partir de 1996, cientos de ellos decidieron explorar y ampliar las rutas migratorias más allá de las fronteras nacionales, en busca de un trabajo que cumpliera las expectativas propias de vida y de sus familias. Fue así que, a través de contactos, llegaron hasta Nueva York. En el transcurso de tres años, la experiencia de ir a Nueva York se había transmitido y compartido entre cientos de personas a través de redes sociales, familiares y de paisanaje que facilitaron la inserción cada vez mayor de indígenas en los flujos migratorios internacionales. La migración actualmente se ha multiplicado de manera importante a nivel familiar, comunitario y municipal hasta incluir en la red a habitantes de una decena de localidades y al menos de seis municipios ubicados en el centro de la Sierra Norte de Veracruz, abarcando los municipios de Tlachichilco, Zontecomatlán, Texcatepec, Zacualpan, Huayacocotla y Chicontepec, 
tratándose de hablantes de diferentes lenguas, pero con el mismo sueño de triunfar en la "gran manzana".

Hombres jóvenes y jefes de hogar, indígenas otomíes, nahuas y tepehuas de la sierra norte del estado son quienes conforman mayoritariamente el flujo migratorio a la ciudad de Nueva York; los lugares de destino se han ido especializando por grupos familiares, sociales, étnicos o lugares de procedencia. Así, los de Tlachichilco se dirigen al oriente de Manhattan, los otomíes a la calle 57 del Bronx y al barrio de Astoria en Queens, los del municipio de Texcatepec van a la calle 140 del Bronx y a los campos agrícolas de New Jersey y Pennsylvania (Zepeda, 2006). Estos patrones migratorios han dado origen a enclaves étnicos; la presencia importante de migrantes de la misma región de origen en Nueva York, el acceso al trabajo y el apoyo de la red han facilitado su formación (Portes y Rumbaut, 1995).

Las redes migratorias veracruzanas han establecido sus nodos en estados norteamericanos tradicionales como Texas, Illinois y California, pero también se han extendido geográficamente hacia lugares no tradicionales y de poca presencia de población latina, como el este de los Estados Unidos: Florida, Carolina del Sur, Carolina del Norte, Washington, Georgia y Nueva York, donde la concentración de trabajadores migrantes procedentes de una misma localidad o región en determinados nichos laborales es muy importante; esto encuentra su explicación en la teoría de las redes sociales, de otra forma ello sería difícilmente posible (Pérez, 2013).

Parece que los indígenas han aprendido los caminos que van desde la sierra de Huayacocotla hasta Nueva York, un espacio social por donde transitan los coyotes que ofrecen sus servicios para cruzar la frontera y donde hay paisanos dispuestos a dar el apoyo solidario que se requiere para ir sumando día a día a todo aquel que se quiera ir.

\section{Recursos migratorios y redefiniciones sociales entre los totonacas}

Las comunidades y municipios de la Sierra de Papantla se caracterizan por ser pueblos con altos índices de marginación, donde se vive con pobreza y con limitado acceso a la educación, en viviendas en malas condiciones, con calles sin pavimentar. En algunos de estos municipios, los campesinos viven de los cultivos de maíz y café principalmente. Hasta finales de los años ochenta, la cafeticultura era rentable, había un buen precio y contaban con el apoyo institucional del Instituto Mexicano del Café (Inmecafe), pero en 1989, con la caída del precio a nivel internacional, la sobreproducción de los mercados mundiales y la desaparición del Inmecafe, los productores se fueron a la quiebra, muchos abandonaron el cafetal, otros lo derribaron para meter otros cultivos o ganado, y algunos más, ante la falta de trabajo, se insertaron en los flujos de migración hacia Ciudad de México y Estados Unidos.

El cultivo de maíz es de gran importancia, no solo en términos económicos, sino también simbólico: es usado para el autoconsumo familiar y un poco para la venta, un ingreso extra lo obtienen de la venta de la hoja de maíz que se utiliza para la elaboración de tamales; los compradores llegan desde Ciudad de México para adquirirla a un precio de 1.300 pesos la 
paca $^{1}$. Si bien este cultivo no significa una ganancia económica importante, los indígenas mantienen su cultivo por tradición y porque, "cuando menos", les permite mantener la dieta alimenticia y garantizar la reproducción social y alimentaria básica, ya se trate de campesinos con tierra propia, que la renten o la siembren a medias.

Algunos campesinos además siembran frijol, chile, calabaza, pipián, ajonjolí y cebolla morada para su venta en el mercado local y el autoconsumo. Un producto importante del campo, que es además nativo de Coyutla, es la pimienta gorda, la cual se exporta y de la que se obtienen buenas ganancias económicas. Hay quienes consideran que trabajar en el campo es una profesión ingrata, sobre todo en los meses de abril y junio, cuando los calores son intensos. Entonces, se sufren y padecen las altas temperaturas cuando se transita entre las parcelas; además, los salarios son muy bajos ( 80 pesos por jornal, equivalente a 4,19 dólares) y resultan ser insuficientes para cubrir la dieta básica (solo alcanzan para comprar azúcar, pan, jabón, maíz, frijol, chile y sopa de pasta, y ocasionalmente un poco de carne de pollo o puerco).

Para ayudar al sostenimiento de la economía familiar campesina, las mujeres venden productos que ellas mismas elaboran como tamales o tortillas, o bien, productos frescos del campo: aguacates, café molido, chiles, naranjas y fríjol. Otras más se emplean en la cosecha del café, en limpiar pepita para obtener pipián y en venderlo por kilo o por bulto, pero esto lo realizan solo en determinados meses del año, obteniendo un pago de entre 100 y 150 pesos al día (equivalente a entre 5,23 y 7,85 dólares). Algunas personas perciben ayudas económicas de los programas sociales gubernamentales, como los denominados Oportunidades, Prospera y Procampo.

Es paradójico el hecho de que algunos campesinos de algunas comunidades de Coyutla emigren por falta de empleo, mientras que por otro lado llegan inmigrantes de tierras altas a cubrirlos y realizar las actividades que ellos han dejado de lado, debido a que son mal pagadas y no están dispuestos a realizar. Algunos inmigrantes llegan de "tierras arriba" a trabajar, provenientes de localidades de los municipios de Filomeno Mata y Mecatlán, y de las comunidades de Huehuetla, Vicente Guerrero y de otras ubicadas en la Sierra Norte de Puebla, donde ganan entre 70 y 80 pesos al día, mientras que en Coyutla reciben hasta 120 pesos por jornal (6,28 dólares).

Al descender de manera importante el cultivo del café (desde finales de la década de 1980), por motivos económicos y personales, los productores indígenas se fueron a la ciudad de Poza Rica, enclave laboral de gran importancia a nivel económico y laboral, a causa de la industria petrolera ahí establecida y el sector servicios que la ciudad demanda. Anteriormente, en la sierra el cultivo del café brindaba trabajo, pero con el desplome de su precio se redujeron las ofertas laborales, por lo que los campesinos se tuvieron que ir de Coyutla, abandonando el cultivo por casi veinte años. Después, cuando el trabajo escaseó en

Cuando se habla de pesos se sobreentiende la alusión a pesos mexicanos ( 1 peso mexicano $=0.052$ dólares estadounidenses a octubre del 2018). La paca es un paquete de un metro cuadrado aproximadamente, que contiene paquetes pequeños de hojas de maíz. Se vende a los comerciantes intermediarios a un precio de 1.300 pesos mexicanos, equivalente a 68 dólares, según el tipo de cambio actual en México. 
Poza Rica, debido a la crisis en la industria petroquímica y en el sector servicios, a mediados de los noventa se ampliaron las rutas migratorias hasta llegar a Ciudad de México, y posteriormente hacia la frontera norte, a Estados Unidos y Canadá. A este último país llegan contratados en el programa de trabajadores temporales que implementan las Secretarías de Trabajo y Previsión Social del Gobierno Federal, en coordinación con los gobiernos de los estados y los empresarios canadienses. Quienes conformaron parte de la migración hacia Estados Unidos fueron los hombres jefes de hogar, luego solteros, familias completas y mujeres solteras. Muchos de ellos se han ido para ya no regresar y otros vuelven de manera temporal o de visita.

Las dinámicas migratorias internacionales protagonizadas por los campesinos de la Sierra de Papantla tuvieron antecedentes de movilidad con destino a diferentes lugares de México, a nivel regional con destino a la ciudad de Poza Rica, donde laboraban en la empresa paraestatal Petróleos Mexicanos o en actividades relacionadas con el sector petrolero y de servicios. Posteriormente se ampliaron las rutas a nivel nacional hacia los estados de Campeche, Tabasco y Puebla, haciendo uso de sus redes sociales y de su experiencia relacionada con la industria del petróleo. A mediados de los noventa, la crisis económica que atravesaba el país se reflejó en la carencia de empleo; fue entonces cuando se dirigieron a diversas ciudades de la frontera norte, donde se empleaban principalmente en el sector maquilador.

En un principio era más común que emigrara el hombre, porque en él recaía la mantención de la casa según las tradiciones locales; era él quien debía salir en busca del sustento, pero con el tiempo esa idea se redefinió y las mujeres adultas y jóvenes empezaron a migrar también ante la falta de oportunidades y de futuro a nivel local. Las causas económicas, sociales y de seguridad personal inciden en las decisiones de migrar a las ciudades de Monterrey, Saltillo y Reynosa, y desde finales de los noventa a Estados Unidos, dando lugar a circuitos migratorios en los que se mueven personas, objetos, ideas, sueños, dinero y mercancías, redefiniendo así las expectativas de los que se quedan y de quienes reinician los viajes al norte.

\section{La presencia de la migración en los espacios locales}

Este circular constante de personas entre territorios de dentro de la sierra y lugares distantes de la costa o las áreas urbanas y rurales, nacionales e internacionales, ha traído costumbres, formas de ser, pensar y divertirse, de hacer y de vestir, que se reflejan en los usos y decoraciones que hacen en sus cuerpos, lo cual ha contrastado las opiniones sobre los cambios y beneficios que las movilidades y migraciones traen consigo para la cultura y la sociedad local. Don Jesús considera que:

algunos migrantes regresan y "se creen"; ya no respetan la lengua totonaca, la consideran una cochinada, discriminan la lengua, traen ropa de cholo, playeras con calaveras, aretes, tatuajes y pulseras, forman bandas. Regresan y son 
mariguanos, alcohólicos, toman cerveza, se vuelven locos y golpean a las personas, y roban. (Jesús, 6 de diciembre de 2011)

Otros consideran que la migración al Distrito Federal y a Estados Unidos afecta de manera diferenciada a la familia y la comunidad porque:

llegan puros cholos, con arete, consumen alcohol. Porque allá se van a vivir a los arrabales, trabajan de obreros y albañiles, y empiezan a consumir drogas; es gente joven que no saben qué. Mientras que los que van a Estados Unidos llegan más maduros, igual, más centrados. (Damián, 16 de junio de 2015)

La migración a Estados Unidos no solo se presenta por causas económicas, sino también por que quienes ya están allá invitan a los hijos y familiares a irse con ellos. Además, la inversión de las remesas en la construcción de viviendas y compra de vehículos también es un aliciente para que los demás se quieran ir. Don Juan considera que: "Hace mal el padre al irse, porque con ello empuja al chamaco a irse tras sus pasos, y quién sabe si mejore o si eche a perder su vida allá. Irse debe nacer del corazón” (Juan, 24 de marzo de 2012). Esto refleja cómo la migración no nace necesariamente de los individuos, sino que se transmite socialmente.

La migración a Estados Unidos iniciada en 2000 cobró importancia a mediados de la década; antes era algo de lo que muy poco se hablaba, y ahora muchos tienen familiares y amigos que se han ido por falta de trabajo, por los bajos salarios que perciben y porque tenían quien los podía ayudar a irse. Algunos migrantes han adquirido conocimientos sobre el proceso migratorio; algunos hasta se han convertido en "coyotes", en personas que cobran por cruzar la frontera e internar a los migrantes a Estados Unidos; otros han invertido sus remesas en la modificación o edificación de sus viviendas, en la compra de parcelas, vehículos y sobre todo en mejorar la calidad de vida de sus familias y en aras de construir los sueños futuros.

Hay quienes consideran que la migración afecta a la comunidad porque los esposos ya no regresan o a su regreso vienen con otra pareja, y porque algunas esposas en la localidad no toleran tanto tiempo vivir la conyugalidad a distancia y se buscan a otro hombre, afectando las relaciones familiares y las expectativas educativas de los hijos. A nivel local, la migración afecta porque las familias se dividen, el marido no regresa y los hijos y la esposa se quedan aquí, teniendo que resolver la vida a su modo, intensificándose las cargas de trabajo para ellos y en ocasiones no pudiendo tomar decisiones libremente porque desde Estados Unidos les dicen lo que tienen que hacer con la tierra y la vida familiar, y el cómo administrar las remesas.

Cabe destacar que si bien la migración trae consigo la mejora de aspectos económicos, hay también visiones encontradas de otros aspectos que implicaría. Hay quienes consideran que la migración genera cambios a nivel social y en los valores tradicionales que mutan de manera acelerada. Don Manuel estima que:

la migración afecta a los que se quedan porque ya no siembran maíz, ni frijol, porque abandonan el campo, dejan de sembrar la tierra al ver que los productos que siembran no tienen valor en el mercado, pero contrariamente dicen, la 
migración es buena, porque si todos viviéramos aquí no tendríamos dónde trabajar, no habría espacio. (Manuel, 6 de diciembre de 2011)

La migración genera empleos temporales por la pérdida de población y por la llegada de remesas económicas. Actualmente. las remesas económicas se pueden hacer efectivas en las cabeceras municipales de la Sierra de Papantla en las empresas privadas, los bancos e instituciones gubernamentales como Sigue, Banamex, Banco Azteca y Telecom, facilitando y abaratando los tiempos y costos de sus usuarios, pues anteriormente tenían que ir hasta la ciudad de Poza Rica, cuyo traslado hasta allá implicaba al menos dos horas en transporte público.

La migración desde la Sierra de Papantla se presenta cuando la gente requiere satisfacer otras necesidades que van más allá de las tradicionales, cuando ya no se requiere vivir solo del autoconsumo. Entonces tienen que ser trabajadores por cuenta propia o asalariados para generar ingresos propios y adquirir otros productos de la canasta básica, vestimenta, construir una casa, comprarse una camioneta o darles educación a los hijos.

Resulta paradójico que, ocasionalmente, a nivel local sí hay trabajo, pero como los habitantes carecían de tierras o solo producían para comer o medio comer, y ya tenían otras expectativas, otras necesidades, los hijos se iban a estudiar fuera de la comunidad. Entonces, la vida ya requería otro tipo de vivienda y el campo de otras inversiones, que solo se podían satisfacer yendo a Estados Unidos. Debido a que el trabajo no era de todos los días, eso sostiene una economía campesina, pero no satisface las expectativas de los nuevos campesinos, que por esa razón migran.

Cuando los migrantes totonacos, sobre todo los internacionales, edifican sus casas en períodos de dos a cuatro años, en lugar de en "toda una vida" como había sido siempre con sus ancestros campesinos, o se compran camionetas u otros bienes, generan en los demás diversas expectativas, planteando la "necesidad" de irse a Estados Unidos. Por eso empiezan a salir, aun cuando en el proceso arriesguen la vida, debido a que la gran mayoría de ellos se van de forma indocumentada, para lo cual contratan a un coyote que les cobra entre 25 y 30 mil pesos por internarlos a la Unión Americana a través del desierto, el río y la montaña.

El dinero de las remesas es empleado para financiar, de manera parcial o completa, los viajes de los nuevos migrantes, sean familiares, amigos o paisanos; en la remodelación y edificación de nuevas y -ante los ojos de los demás- majestuosas viviendas; también, en la compra de camionetas y en la siembra de la tierra. Los rubros más importantes de gasto e inversión social de las remesas se hacen en alimentación, educación, salud y vestimenta; algunos migrantes apoyan con su cooperación para la mejora de las iglesias, para la realización de fiestas religiosas y para la ejecución de danzas tradicionales.

En los municipios de la Sierra de Papantla también hemos identificado procesos de movilidad que se han ido redefiniendo en el tiempo. Respondiendo a diversos factores, se han incorporado primero los hombres jóvenes y adultos, y posteriormente mujeres y familias completas, con destino a lugares rurales de la región, o urbanos como Papantla y Poza Rica, 
y de larga distancia como las ciudades de México y Monterrey, a lo largo de la frontera norte, así como a Estados Unidos. Recientemente, a través de un proceso de enganche mediado por el Estado, los indígenas han ido a vender su fuerza de trabajo temporalmente a Chihuahua, Sonora y Puebla, incluso hasta a Canadá, conformando un circuito complejo migratorio transnacional.

El denominado Subprograma de Movilidad Laboral Interna, dependiente de la Secretaría del Trabajo y Previsión Social (STPS) que opera a nivel federal en diversos estados del país, se encarga de coordinar la movilización de jornaleros agrícolas a diversas empresas agrícolas de México y Canadá. En el norte de Veracruz, una de las oficinas opera en la ciudad de Poza Rica, donde los migrantes llegan en busca de oportunidades de contratarse: son cientos de campesinos e indígenas provenientes de los municipios de Zozocolco de Hidalgo, Filomeno Mata, Espinal, Coyutla y Mecatlán, no así de Coxquihui, que también forma parte de la Sierra de Papantla, para realizar actividades temporales correspondientes a la cosecha de productos agrícolas en Puebla, Chihuahua y Sonora, solo por citar algunos (Moncada, 17 de junio de 2011).

Desde el año 2008, la participación de los totonacos en los programas de trabajo temporal ha cobrado particular importancia, debido a la oferta de plazas que se amplía cada vez; antes se contrataban entre 40 y 50 trabajadores, actualmente se hacen envíos de más de 100 trabajadores. De enero a junio del 2011 se realizaron tres envíos a los estados de Sonora: al corte de la uva, a Sinaloa a los campos de jitomate y algunos más que fueron requeridos en el estado de Chihuahua, adonde van al desahíje, limpieza de cultivos y al corte de manzana u otros productos (González, 17 de junio de 2011).

Del municipio de Filomeno Mata, de octubre a noviembre de 2010 enviaron a entre 300 y 350 trabajadores a las fincas cafetaleras del estado de Puebla para realizar actividades de cosecha, algunos de los cuales viajan con todo y familias, otros van de manera permanente y/o hay quienes "van y vienen a diario"; esto debido a la poca capacidad de los albergues para sostener tan numerosa población por períodos más largos.

En cada estado, el personal de la oficina del Servicio Estatal de Empleo sería el encargado de vigilar y supervisar el cumplimiento tanto de las condiciones laborales como de las instalaciones donde se albergarán los trabajadores durante los períodos de contrato. Sin embargo, en la praxis, lo estipulado en los contratos no siempre se cumple: ni los salarios, ni los tiempos de trabajo, ni las condiciones de seguridad en los albergues. Los trabajadores que acuden no requieren necesariamente experiencia específica; en general, dominan actividades relacionadas con el medio agrícola, son dóciles y obedientes, además de resistir las arduas jornadas laborales, muchas veces bajo el sol. Estas condiciones son las que les permitirían ser contratados posteriormente por ser "buenos trabajadores" de acuerdo a la conveniencia del patrón, pues no oponen resistencia a lo ordenado ni "alborotan" a los otros trabajadores en relación al reclamo de respeto de sus derechos laborales y humanos.

El Subprograma de Movilidad Laboral Interna de la STPS se encarga de mediar la concreción del contrato o enganche de trabajadores que se requieren en los campos agrícolas de Sonora, 
Sinaloa, Puebla y Chihuahua. Como referencia, de enero a junio de 2011 se inscribieron 200 indígenas de Zozocolco de Hidalgo y 50 de Ixhuatlán de Madero para el desempeño de actividades relacionadas con la cosecha y el deshierbe de cultivos. Para llegar hasta las fincas donde desempeñan sus labores, los trabajadores cubren los costos del transporte, pero reciben un apoyo de 1.400 pesos ( 73 dólares según el tipo de cambio actual) por parte de la Secretaría del Trabajo. El salario es variable y va desde los 120 hasta los 130 pesos por jornal (de los 6,28 a los 6,80 dólares).

La movilidad de los totonacos hacia Canadá es muy reciente, pero cobra importancia cada vez mayor, a partir de su participación en el Subprograma de Movilidad Laboral Interna establecido entre el gobierno de México y empresarios canadienses. En años anteriores, como 2008, se contrataban únicamente a 40 personas de la región totonaca; no obstante, el número aumentó a 350 apenas dos años después, lo cual depende de la cantidad de plazas vacantes que se ofrezcan en el ciclo. Algunos de los campesinos e indígenas que se inscriben en el programa provienen del municipio de Coyutla y acuden por un período máximo de ocho meses. Este programa funciona en México desde 1974, pero es desde 2004 que opera en la región norte de Veracruz con cada vez más inscritos; a partir de 2010 han participado cerca de mil trabajadores (González, 17 de junio de 2011).

La inscripción en el programa depende de que los empleadores los requieran y del desempeño que hayan tenido en lo laboral y en su comportamiento personal para quienes hayan participado con anterioridad en los campos agrícolas canadienses: si fueron obedientes y no ocasionaron problemas, se les extiende la invitación para regresar. El proceso está en manos de tres dependencias: el Ministerio del Trabajo de Canadá, la Secretaría de Relaciones Exteriores y la STPS de México. Esta última tiene sus oficinas en la ciudad de Poza Rica; desde allí se encarga de recibir y emitir cartas, y de convocar y publicitar el programa entre los campesinos totonacas en sus localidades de origen.

A Canadá solo van campesinos e indígenas provenientes de la Sierra de Papantla: Espinal, Coxquihui y Coyutla, quienes se dirigen a las provincias de Ontario, Columbia Británica, Quebec y Alberta, en donde realizan actividades agrícolas como siembra y cosecha de verduras, corte de frutas (durazno, manzana), además de trabajar en invernaderos y empacadoras de flores. Si bien la mayoría de quienes van a Canadá son hombres, se hace evidente la participación cada vez mayor de mujeres, quienes realizan actividades de empaque de frutas y flores. Los salarios que perciben cuando hay trabajo es de 9,50 a 10,50 dólares canadienses por hora menos impuestos, y cubren jornadas de 12 horas diarias en promedio (González, 17 de junio de 2011).

Si bien el contrato de trabajo dura como máximo ocho meses y los salarios que se perciben son más bajos que los que se obtienen como trabajador indocumentado en Estados Unidos, la movilidad laboral temporal hacia Canadá se está convirtiendo en una opción cada vez más socializada y viable, en tanto que resulta más barato que pagarle 40 mil pesos a un coyote para ser pasado a Estados Unidos, y no se arriesga la vida en el desierto o en el cruce de frontera; además es un empleo más o menos seguro, a diferencia de lo que sucede en Estados Unidos, donde cada vez es más difícil, lento y caro conseguir un empleo redituable. Sin duda, 
la información que los migrantes traen o hacen circular a su retorno, influye en los cambios de expectativas de la migración para tomar la decisión más segura para sus acciones futuras.

\section{La ruralidad en los procesos migratorios}

Las expectativas y aspiraciones de los hombres del medio rural se han venido redefiniendo a través del tiempo. En el aspecto laboral han cambiado las rutas y lugares de trabajo, las formas y condiciones de contratación; en algún momento, algunos campesinos migraban a nivel regional: en tiempos de cosecha se dirigían a diversas comunidades que los requerían, y posteriormente se dificultó el proceso de reclutamiento de trabajadores porque estos ya se habían ido a Estados Unidos. La carencia de mano de obra en algunos municipios de la región no solo se presentó en las actividades agrícolas, sino también en las relacionadas con la industria de la construcción y de la petroquímica, ramo en el que muchos de los migrantes participaban.

La antropóloga Lourdes Arizpe (1985) apunta que la migración no se presenta únicamente debido a factores económicos, sino también a causa de la "revolución de aspiraciones", es decir, que la gente ya no se conforma solo con trabajar por un ingreso que les permita subsistir, sino que aspira obtener uno que verdaderamente mejore sus condiciones de vida. Los cambios sociales, las redefiniciones históricas de las formas de vida y visiones del mundo de las poblaciones rurales, se dan por su incorporación a una sociedad nacional y su participación en los circuitos de migración internacional, por los efectos de la globalización cultural y por el American way of life (Gledhill, 1998).

Los migrantes y los no migrantes, a través de la socialización de las experiencias de trabajo allende la frontera, han ido transmitiendo la idea de bienestar del trabajo en Estados Unidos, dando paso así a la conformación de un imaginario colectivo de lo que significa "trabajar": "de un par de años a la fecha, trabajar ya no es hacer producir la tierra o quedarse en la parcela, sino ir a los Estados Unidos, ganar dólares” (Damián, 16 de junio de 2015).

Lo que contribuirá a la redefinición de la ruralidad y de las relaciones diversas con la tierra, la migración y las expectativas de futuro, se ve influido por los espacios que se habitan y los recursos que los nodos regionales -laborales, comerciales o de desarrollo- ofrecen, de manera diferenciada en la sierra, la llanura costera o la ciudad petrolera de Poza Rica. Los valores entre los jóvenes y las poblaciones adultas, el significado simbólico y real de la tierra sobre el trabajo, orientan las distancias o destinos de los flujos migratorios.

Los indígenas totonacos y habitantes de la sierra papanteca están insertos desde hace varias décadas en diversos tipos de movilidades y migraciones, desarrollando formas de interacción social que los llevan a diversas lugares y áreas de trabajo rurales y urbanos, más dinámicos y comunicados, participando en una amplia gama de actividades productivas en las que se desempeñan como obreros, albañiles, electricistas, empleados y jornaleros agrícolas. Hombres adultos, jóvenes, mujeres y niños forman parte de los flujos en las sucesiones

migratorias que se habían venido redefiniendo debido a las conductas sedentarias que se 
institucionalizaron a lo largo del tiempo, situación que había retenido su incorporación a la migración internacional en un momento más temprano. Las redes muestran cierta fragilidad desde el principio de su formación; sin embargo, algunas cuentan con actores dinámicos y aceleradores de la migración.

Por otra parte, aunque en un principio las redes de mayor valía en la socialización e inclusión de los migrantes eran las de tipo familiar, de compadrazgo, hoy tienen más peso las relaciones y vínculos de amistad y paisanaje. Las que muestran mayor densidad, por pequeñas que sean, son las que involucran a varios actores en tiempos cortos, a diferencia de las difusas, que por su limitada cantidad y calidad de recursos que poseen solo permiten migrar a unos cuantos de sus integrantes.

\section{Conclusiones}

La migración a Estados Unidos se presenta con un desarrollo lento por ser muy costosa, en relación con los niveles locales de ingreso, pues se tienen que pagar sumas de 25 a 30 mil pesos (entre 1.300 y 1.570 dólares, según el tipo de cambio actual en México) para ser internado de manera indocumentada, lo cual se acentúa en razón de que la economía indígena rural de subsistencia no permite reunir ese monto en tiempos cortos. Además, juntar el dinero se complejiza porque los nodos de las redes migratorias, que lo podrían proveer, se hayan multisituados geográficamente y en ciernes, y hasta el momento no han generado la estructura necesaria para sostener el fenómeno.

Estas movilidades sociales, redefinidas a través de las geografías, las interacciones sociales y los tiempos, han conformado un circuito migratorio complejo que ha llevado a los habitantes de la Sierra de Papantla a incursionar en mercados de trabajo indígenas rurales (como son el corte de café, el chapeo de fincas ${ }^{2}$ o el cuidado de ganado) y a mercados urbanos regionales de la Ciudad de México, a las maquilas de la frontera norte, a los Estados Unidos y recientemente a Canadá.

Los indígenas totonacos han transitado por diversas escalas geográficas, sociales y temporales, vendiendo su fuerza de trabajo a nivel local, regional, nacional, fronterizo e internacional, lo cual conlleva procesos de redefinición de sus expectativas y de las formas de relacionarse con la tierra, con la cultura local y con la forma de reproducción identitaria tradicional.

Los diferentes tipos de migración en que se insertan los totonacos han traído efectos diferenciados por comunidad o familia. Económicamente, la inversión de remesas trae cambios en el paisaje rural, como construcción de casas e inversión en tierras y camionetas, situaciones que influyen en la redefinición de las expectativas de los migrantes y no migrantes. Las remesas que llegan a las familias se invierten de manera recurrente en

2 Chapeo es la actividad de limpieza del terreno agrícola, eliminación de maleza o hierbas que impiden el crecimiento idóneo de los cultivos. 
alimentación, salud y educación, posibilitando la mejora de las condiciones de vida de quienes se quedan. Si bien los beneficios económicos de las migraciones son visibles, también hemos identificado costos socioemocionales en las esposas e hijos: la ausencia de la figura paterna tiene consecuencias en los roles y formas de vivir la separación familiar, situaciones que deben investigarse en el futuro.

La transformación de la vestimenta y los peinados, el declive del uso de la lengua totonaca, el consumo de alcohol y de otras sustancias empiezan a tener impacto entre los que se quedan, que ven como riesgo el que los jóvenes salgan de la comunidad. La pérdida del respeto a la tierra, el trabajo, a los otros y a las propiedades privadas, dicen los adultos, es algo que ha venido con la gente que sale de las comunidades. En esto ha de ponerse atención porque redefine las formas de interacción social.

Las migraciones indocumentadas hacia Estados Unidos y las de contrato a través del Subprograma de Movilidad Laboral Interna de la STPS han permitido la conformación de diversas redes sociales y de capital humano que juegan un papel muy importante para sostener el fenómeno. Las redes son procesos de organización social formal e informal con recursos sociales y económicos inyectados que son de gran valía para reducir los costos y los riesgos que implica para los migrantes de reciente inserción.

Las dinámicas de la migración internacional presentan matices diferenciados por regiones, tiempos y sociedades, y se redefinen de manera acelerada en función de los contextos rurales regionales e internacionales, de ahí la importancia de realizar investigaciones y lecturas de la realidad en equipos de trabajo no solo interdisciplinarios sino también interinstitucionales.

Los procesos migratorios presentaron cambios importantes desde fines de la década de 1980, por ejemplo, cuando dejó de ser un fenómeno familiar y regional, para volverse masculino e internacional; también ha habido transformaciones relativas a los elevados costos humanos y económicos que se deben cubrir, y asimismo hay efectos en los tejidos sociales, más evidentes a nivel familiar. Para finales de la década de 1990, los cambios se hicieron evidentes por la participación nuevamente de mujeres y niños, quienes fueron estableciendo gradualmente su residencia en Estados Unidos.

La migración aceleró el proceso de redefinición de las expectativas y formas de vida de los miembros del medio rural, lo habiten o no, pues la presencia virtual de quienes están en Estados Unidos es determinante para quienes se encuentran en las comunidades de origen en México. Este ir y venir entre ambos países permitió a los hombres pasar de campesinos a migrantes, y adquirir los conocimientos necesarios para convertirse después en coyotes regionales y locales, teniendo un peso específico de acción en los lugares donde ofrecían sus servicios.

La inserción de cada vez más hombres a los flujos migratorios internacionales, el transcurso del tiempo y la acumulación de capital humano y social permitieron la formación de redes sociales, basadas en vínculos familiares, de compadrazgo y paisanaje que facilitaron el desarrollo del fenómeno. Entre estos grupos sociales se interactuaba de manera constante, se 
fortalecían los lazos de solidaridad y se compartían los recursos sociales y económicos inyectados en las redes, las cuales eran de composición diversa, como también lo era la movilidad de los hombres que las integraban, dependiendo de si estaban insertos en interacciones sociales más o menos consistentes en los diferentes escenarios geográficos.

Los destinos y lugares iniciales a los que se dirigen los migrantes de estos municipios se han ido redefiniendo constantemente, pero la migración a Estados Unidos y Canadá presenta una característica particular, al dejar de establecerse en un solo lugar y dar lugar a la dispersión geográfica, de asentamientos poblacionales y a una alta movilidad por distintos estados de la Unión Americana en busca de la seguridad laboral, personal o evitando ser deportados, criminalizados o discriminados. Estos migrantes han dejado atrás las actividades del campo, ligadas al trabajo de la tierra, para realizar las propias de las áreas urbanas, instalándose en fábricas, tiendas, restaurantes tradicionales y de comida rápida.

\section{Referencias}

Arizpe, L. (1985). Campesinado y migración. Ciudad de México: SEP.

Castilla, E., Hwang, H. Granovetter, M. y Granovetter, E. (2000). Social Networks in Silicon Valley. En Ch-M. Lee, W. Miller, M. Gong (Eds.), The Silicon Valley Edge (pp. 218 247). Stanford: Stanford University Press.

COESPO (2002). La migración en el estado de Veracruz, 1930-2000. Veracruz: Consejo Estatal de Población.

Conapo (2002). La población de México en el nuevo siglo. Ciudad de México: Conapo.

Cruz, R. (2012). Cambios fronterizos y movimientos migratorios en la frontera norte de México. En T. Ramírez y M. A. Castillo (Coords.), El estado de la migración ante los recientes desafios de la migración internacional (pp. 157-184). Ciudad de México: Conapo.

Damián (16 de junio de 2015). Entrevista de Mario Pérez Monterosas.

Durand, J. (1994). Más allá de la línea: patrones migratorios entre México y Estados Unidos. Ciudad de México: CNCA.

EMIF (2004). Encuesta de la migración en la frontera norte 2000-2001. Ciudad de México: El Colegio de la Frontera Norte-Conapo.

EMIF (2008). Encuesta de la migración en la frontera norte 2005-2006. Ciudad de México: El Colegio de la Frontera Norte-Conapo. 
EMIF (2013). Encuesta de la migración en la frontera norte 2010-2011. Ciudad de México: El Colegio de la Frontera Norte-Conapo.

Gatti, L. y Chenaut, V. (1987). La costa totonaca: cuestiones regionales II. Ciudad de México: CIESAS.

Gledhill, J. (1998). ¿Se puede pensar en otra modernidad rural? En S. Zendejas y P. de Vries (Eds.), Las disputas por el México rural, Vol. 1 (pp. 101-132). Zamora: El Colegio de Michoacán.

González, G. (2006). Migración internacional mexiquense. Ponencia presentada en el diplomado de estudios migratorios, El Colegio de Michoacán-UMSNH.

González (17 de junio de 2011). Entrevista de Mario Pérez Monterosas.

Griego, D., Muñoz, A., Pérez, A. y Salazar, S. (2003). Memoria de encuentros indígenas en Veracruz. 1995-2001. Xalapa: MAIZ.ASER-Conaculta-IVEC.

Ibarra, G. (2003). Migrantes mexicanos en la industria del vestido de Los Ángeles. Migraciones Internacionales, 2(1), 107-135.

INEGI (1995). Conteo de Población. INEGI, México.

INEGI (2000). Censo Nacional de Población y Vivienda. INEGI, México.

INEGI (2005). Conteo de Población. INEGI, México.

INEGI (2010). Censo Nacional de Población y Vivienda. INEGI, México.

Jesús (6 de diciembre de 2011). Entrevista de Mario Pérez Monterosas.

Juan (24 de marzo de 2012). Entrevista de Mario Pérez Monterosas.

Kemper, R. (1987). Urbanización y desarrollo en la región tarasca a partir de 1940. En G. de la Peña (Comp.), Antropología de la región purhépecha (pp. 67-96). Michoacán: El Colegio de Michoacán.

Manuel (6 de diciembre de 2011). Entrevista de Mario Pérez Monterosas.

Massey, D. S., Alarcón, R., Durand, J. y González, H. (1987). Return to Aztlan: The Social Process of International Migration from Western Mexico. Berkeley: University of California Press. 
Mestries, F. y Pérez, M. (2014). El estudio de los flujos migratorios emergentes hacia y desde el norte: el caso de Veracruz (1995-2012). En A. Nava y P. Leite (Coords.), 20 años de la Encuesta sobre Migración en la frontera norte de México (pp. 159-186). Ciudad de México: Conapo.

Moctezuma, S. (2008). Ambiente, cafeticultura y migración: los indígenas totonacos de Naranjales, Mecatlán, Veracruz (Tesis de maestría en Antropología Social). Universidad Iberoamericana, Ciudad de México.

Moncada (17 de junio de 2011). Entrevista de Mario Pérez Monterosas.

Pérez, M. (2013). Tejedores de caminos. Redes sociales y migración internacional en el centro de Veracruz. Michoacán: El Colegio de Michoacán.

Portes, A. y Rumbaut, R. (1995). Immigrant America. A portrait. Berkeley: University of California Press.

Secretaría de Relaciones Exteriores (1997). Estudio binacional sobre la migración MéxicoEstados Unidos. Ciudad de México: Autor.

Tilly, C. (1990). Transplanted Networks. En V. Yans-McLaughlin (Ed.), Immigration Reconsidered. History, Sociology, and Politics (pp. 79-95). Oxford: Oxford University Press.

Velasco, L. (2002). El regreso de la comunidad: migración indígena y agentes étnicos. Los mixtecos en la frontera México-Estados Unidos. Ciudad de México: El Colegio de la Frontera Norte.

Wiest, R. (1977). Some Implications of International Labor Migration for Mexican Rural Development. Winnipeg: University of Manitoba.

Zepeda, A. (noviembre de 2006). Donde el tiempo te persigue. Ojarasca. Recuperado de http://www.jornada.unam.mx/2006/11/13/oja115-alfzepeda.html

Cómo citar este artículo: Pérez, M. (2018). Las migraciones en el norte de Veracruz, México. Redes, rutas y ruralidades. Si Somos Americanos. Revista de Estudios Transfronterizos, 18(2), 34-52. 